\title{
Photocatalytic Degradation of Trifluralin, Clodinafop-Propargyl, and 1,2-Dichloro-4-Nitrobenzene As Determined by Gas Chromatography Coupled with Mass Spectrometry
}

\author{
Niyaz A. Mir, ${ }^{1}$ A. Khan, ${ }^{1}$ M. Muneer, ${ }^{1}$ and S. Vijayalakhsmi ${ }^{2}$ \\ ${ }^{1}$ Department of Chemistry, Aligarh Muslim University, Aligarh, Uttar Pradesh 202002, India \\ ${ }^{2}$ SAIF, CRNTS, IIT Bombay, Powai, Mumbai 400076, India \\ Correspondence should be addressed to M. Muneer; readermuneer@gmail.com
}

Received 30 May 2014; Revised 17 July 2014; Accepted 17 July 2014; Published 31 August 2014

Academic Editor: Teresa Kowalska

Copyright (C) 2014 Niyaz A. Mir et al. This is an open access article distributed under the Creative Commons Attribution License, which permits unrestricted use, distribution, and reproduction in any medium, provided the original work is properly cited.

\begin{abstract}
Phototransformation is considered one of the most key factors affecting the fate of pesticides. Therefore, our study focused on photocatalytic degradation of three selected pesticide derivatives: trifluralin (1), clodinafop-propargyl (2), and 1,2-dichloro-4nitrobenzene (3). The degradation was carried out in acetonitrile/water medium in the presence of titanium dioxide $\left(\mathrm{TiO}_{2}\right)$ under continuous purging of atmospheric air. The course of degradation was followed by thin-layer chromatography and gas chromatography-mass spectrometry techniques. Electron ionization mass spectrometry was used to identify the degradation species. GC-MS analysis indicates the formation of several intermediate products which have been characterized on the basis of molecular ion, mass fragmentation pattern, and comparison with NIST library. The photocatalytic degradation of pesticides of different chemical structures manifested distinctly different degradation mechanism. The major routes for the degradation of pesticides were found to be (a) dealkylation, dehalogenation, and decarboxylation, (b) hydroxylation, (c) oxidation of side chain, if present, (d) isomerization and cyclization, (e) cleavage of alkoxy bond, and (f) reduction of triple bond to double bond and nitro group to amino.
\end{abstract}

\section{Introduction}

The contamination of water bodies due to the presence of pesticides constitutes a pervasive problem and therefore advanced methods are in demand for the effective treatment of these pesticide polluted ground and surface waters. Advanced oxidation processes have proven effective for the removal of organic pollutants. During the last two decades, photocatalytic processes involving semiconductor particles under UV light illumination have been shown to be potentially advantageous and useful in the degradation of organic pollutants [1-3]. The process occurs as a result of the interaction of a semiconductor photocatalyst and UV radiation that yields highly reactive hydroxyl and superoxide radical anions, which are believed to be the main species responsible for the oxidation of organic substrates. The most commonly used photocatalyst is $\mathrm{TiO}_{2}$, which is inexpensive, abundant, photostable, and nontoxic [4]. The mechanism of photocatalysis is well documented in the literature $[4,5]$. Briefly, when a semiconductor such as $\mathrm{TiO}_{2}$ absorbs a photon of energy equal to or greater than its band gap energy, an electron may be promoted from the valence band to the conduction band $\left(\mathrm{e}^{-}\right)$leaving behind an electron vacancy or "hole" in the valence band $\left(\mathrm{h}^{+}\right)$, as shown in (1). If charge separation is maintained, the electron and hole may migrate to the catalyst surface where they participate in redox reactions with sorbed species $[6,7]$. In particular, $\mathrm{h}^{+}$ may react with surface-bound $\mathrm{H}_{2} \mathrm{O}$ to produce the hydroxyl radical and $\mathrm{e}^{-}$is picked up by oxygen to generate superoxide radical anion $\left(\mathrm{O}_{2}^{-}\right)$, as indicated in (2) and (3):

$$
\begin{gathered}
\mathrm{TiO}_{2}+h v \longrightarrow \mathrm{TiO}_{2}{ }^{*}\left(\mathrm{e}^{-}+\mathrm{h}^{+}\right) \\
\mathrm{e}^{-}+\mathrm{O}_{2} \longrightarrow \mathrm{O}_{2}^{\cdot-} \\
\mathrm{H}_{2} \mathrm{O}+\mathrm{h}^{+} \longrightarrow \mathrm{OH}^{\cdot}+\mathrm{H}^{+}
\end{gathered}
$$


The photocatalyzed degradation of pesticides does not occur directly to release inorganic species but through the formation of prolonged intermediates or degradation products which can themselves be toxic and, in some cases, more persistent than the original substrate [8-10].

Therefore detection and identification of the degradation products during photocatalytic treatment are important to optimize and increase the overall efficiency of the process. However, the intricacy of the reaction pathways, formation of numerous by-products, and the broad range of concentration and polarity of intermediated products are some of the problems faced during analytical determination of degradation products. Therefore careful analytical screening using diverse techniques is essential to examine the various possible transformation routes and to understand and propose the reaction pathways [11].

Due to the complexity of the electron/radical induced reactions occurring during the photocatalytic processes, it is difficult to suggest a comprehensive reaction pathway explaining the formation of all detected intermediates. However, a comparatively adequate number of fairly abundant degradation products have been recognized during the process, so that a probable scheme can be suggested considering the common transformation processes of other organic compounds [11]. Gas chromatography coupled with mass spectrometry is one of the most frequent analytical tools used for the detection of degradation products [12-14].

Trifluralin (2,6-dinitro-N,N-dipropyl-4-(trifluoromethyl) aniline) (1), a dinitroaniline herbicide, is one of the most common herbicides used to control many annual grasses and broadleaf weeds for agricultural crops [15]. Trifluralin is currently registered in more than 50 countries for use on over 80 crops [16]. It is currently the 3 rd and 4 th most commonly used herbicide on cotton and soybean, respectively. Due to its hydrophobic nature, it strongly sorbs to soil and therefore its transport to the surface and ground water in the dissolvedphase is very limited. Offsite transport mainly takes place by soil erosion and subsequent deposition into streams and lakes or by volatilization losses following field applications [17-20]. Trifluralin has been classified as group C possible human carcinogen and possesses relatively high toxicity for aquatic organisms. Moreover, trifluralin is suspected to be an endocrine disruptor [21].

Clodinafop-propargyl (2-propynyl (R)-2-[4-(5-chloro3-fluoro-2-pyridinyloxy)phenoxy]propionate) (2) is a systemic, postemergence herbicide that effectively controls isoproturon-resistant little seed canary grass biotypes (Phalaris minor Retz.) along with other broad-leaved weeds of wheat (Triticum aestivum) [22-26]. This herbicide is used in combination with a safener, cloquintocet-mexyl, but has an antagonistic effect with auxin-type herbicides [27]. It interferes with the production of fatty acids needed for plant growth in susceptible grassy weeds [28]. This herbicide breaks down rapidly in soil and is mobile in soil. The toxicity data indicates that clodinafop-propargyl has low acute oral, dermal, and inhalation toxicity. It has been classified as "likely to be carcinogenic to human" causing developmental and fetotoxicity in rats. This product has been found to be moderately toxic to aquatic organisms (human health risk assessment for the use of the new active ingredient, clodinafop-propargyl, on wheat, United States Environmental Protection Agency, Office of Prevention, Pesticides and Toxic Substances, Washington, DC).

Chloronitrobenzenes are important chemical intermediates in the manufacture of dyes and agricultural, pharmaceutical, and industrial agents [29-33]. The toxicity induced by chloronitrobenzenes includes hematoxicity, sphenotoxicity, hepatotoxicity [34-36], and immunotoxicity [37, 38].

Therefore in this paper we report the photocatalytic transformation of three selected pesticide derivatives: trifluralin (1), clodinafop-propargyl (2), and 1,2-dichloro-4nitrobenzene (3) in acetonitrile/water medium catalyzed by $\mathrm{TiO}_{2}$ in the presence of atmospheric oxygen and UV light.

\section{Experimental}

2.1. Reagents and Chemicals. The analytical standard trifluralin (1), clodinafop-propargyl (2), and 1,2-dichloro-4nitrobenzene (3) were purchased from Sigma-Aldrich, India, and were used without further purification. Heterogeneous photocatalytic transformation experiments were carried out using Degussa P-25 $\mathrm{TiO}_{2}$ (Degussa AG). Degussa P25 consists of $80 \%$ anatase and $20 \%$ rutile with a specific BETsurface area of $50 \mathrm{~m}^{2} \mathrm{~g}^{-1}$ and primary particle size of $20 \mathrm{~nm}$ [39]. All other chemicals used in this study like acetonitrile $\left(\mathrm{CH}_{3} \mathrm{CN}\right)$, sodium sulphite $\left(\mathrm{Na}_{2} \mathrm{SO}_{3}\right)$, chloroform $\left(\mathrm{CHCl}_{3}\right)$, and so forth were of analytical grade and obtained from Merck.

2.2. Procedure. Experiments were carried out in an immersion well photoreactor made of Pyrex glass equipped with a magnetic bar, a water circulating jacket, and an opening for molecular oxygen. A detailed description of photocatalytic reactor was documented in our previous paper [40]. In a typical run, $\mathrm{TiO}_{2}$ (Degussa, P25 $1.5 \mathrm{gL}^{-1}$ ) was added to acetonitrile/water $(1: 6)$ solution of trifluralin $(1.22 \mathrm{mM} ; 180 \mathrm{~mL})$ or clodinafop-propargyl (1.22 mM; $180 \mathrm{~mL})$ or 1,2-dichloro4 -nitrobenzene $(1.24 \mathrm{mM} ; 180 \mathrm{~mL})$. The suspensions were continuously purged with molecular oxygen throughout each experiment. Irradiations were carried out using a $125 \mathrm{~W}$ medium pressure mercury lamp (Philips) placed at the centre of the inner jacket. The light intensity was measured at the inner wall of the annular reactor using UV-light intensity detector (Lutron UV-340) and was found in between 1.92 and $1.95 \mathrm{~mW} / \mathrm{cm}^{2}$. IR-radiations were eliminated by a water jacket. Aliquots $(10 \mathrm{~mL})$ were withdrawn at different time intervals and filtered using Whatman grade number 1 filter paper to remove the $\mathrm{TiO}_{2}$ particles. The filtrate was extracted at least thrice with chloroform $(10 \mathrm{~mL})$ and dried over anhydrous sodium sulphate and the solvent was removed under reduced pressure to give a residual mass. The formation of products was followed using thin-layer chromatography technique and then finally analyzed by GCMS analysis technique. $\mathrm{CHCl}_{3}$ was used to reconstitute the sample of trifluralin and clodinafop-propargyl for GC-MS analysis whereas $\mathrm{CH}_{3} \mathrm{CN}$ was used as solvent for 1,2-dichloro4-nitrobenzene. 
TABLE 1: Probable products formed during the photocatalytic degradation of trifluralin (1) along with their retention time and corresponding mass fragmentation.

\begin{tabular}{|c|c|c|c|}
\hline $\begin{array}{l}\text { Retention time } \\
(\mathrm{min})\end{array}$ & Name & Confirmed by & Mass fragmentation \\
\hline 9.4 & $\begin{array}{l}\text { 2,6-Dinitro-N,N-dipropyl-4- } \\
\text { (trifluoromethyl)aniline } \\
\text { (1) }\end{array}$ & NIST & $\begin{array}{l}335.142\left(\mathrm{M}^{+}\right), 318.138,306.136 / 307.105,290.105 \\
264.076 / 265.053,248.054,206.051,160.049,145.035\end{array}$ \\
\hline 9.9 & $\begin{array}{l}\text { 2-Ethyl-7-nitro-5-(trifluoromethyl)-1H- } \\
\text { benzo[d]imidazole } \\
\text { (12) }\end{array}$ & NIST & $\begin{array}{l}259.157\left(\mathrm{M}^{+}\right), 241.123,227.105,213.095,207.014,199.073 \\
186.098,158.187,147.827,114.459,99.536,54.368\end{array}$ \\
\hline 11.0 & $\begin{array}{l}\text { 2-Ethyl-7-nitro-1-propyl-5- } \\
\text { (trifluoromethyl)-1H-benzo[d]imidazole } \\
\text { (9) }\end{array}$ & NIST & $\begin{array}{l}301.134\left(\mathrm{M}^{+}\right) / 302.143,282.140,272.098,258.078 \\
243.087 / 244.094,212.077 / 213.083,159.043,145.037\end{array}$ \\
\hline 12.7 & $\begin{array}{l}\text { 7-Amino-2-ethyl-1-propyl-5- } \\
\text { (trifluoromethyl)-1H-benzo[d]imidazole } \\
\text { 3-oxide (7) }\end{array}$ & MS & $\begin{array}{l}287.150\left(\mathrm{M}^{+}\right) / 288.159,258.113 / 259.124,245.103,230.82 \\
217.069,202.083\end{array}$ \\
\hline 12.9 & $\begin{array}{l}\text { 3-(2-(Hydroxyamino)-6-nitro-4- } \\
\text { (trifluoromethyl)phenylamino)propan-1-ol } \\
\text { (10) }\end{array}$ & MS & $\begin{array}{l}\text { 295.164 }\left(\mathrm{M}^{+}\right) / 296.177,280.140,266.123,252.111 / 23.111 \\
\text { 239.112, 225.095 }\end{array}$ \\
\hline 13.0 & $\begin{array}{l}\text { 2-Ethyl-1-propyl-5-(trifluoromethyl)-1H- } \\
\text { benzo[d]imidazol-7-amine } \\
\text { (11) }\end{array}$ & MS & $271.155\left(\mathrm{M}^{+}\right) / 272.160,256.131,242.113,229.104 / 228.097$ \\
\hline 15.2 & $\begin{array}{l}\text { 3-(2,6-Dinitro-4- } \\
\text { (trifluoromethyl)phenylamino)propan-1-ol } \\
\text { (6) }\end{array}$ & MS & $\begin{array}{l}310.171\left(\mathrm{M}^{+}\right), 295.153,283.159 / 284.162,268.134,254.116 \\
240.101,227.102,213.089 / 214.091,185.057\end{array}$ \\
\hline
\end{tabular}

Note that the number in the parenthesis corresponds to the number of the compound in the degradation scheme.

2.3. Analysis. For GC-MS analysis, AccuTOF-GCv (JMST100GCv) system from Jeol Asia equipped with Agilent 7690 GC was used. The GC column for separation was a HP-5, $30 \mathrm{~m}$ long, and $0.25 \mathrm{~mm}$ internal diameter. The film thickness was $0.25 \mu \mathrm{m}$. The column temperature programme used was $100^{\circ} \mathrm{C}$ initially with an isothermal hold time for $5 \mathrm{~min}$ and then rose to $280^{\circ} \mathrm{C}$ at a ramp of $10^{\circ} \mathrm{C} / \mathrm{min}$. The injector temperature was $250^{\circ} \mathrm{C}$ and the injection volume was $0.4 \mu \mathrm{L}$, with a split ratio of $1: 50$. The interface temperature was maintained at $280^{\circ} \mathrm{C}$. The carrier gas was helium with a flow rate of $1 \mathrm{~mL} / \mathrm{min}$. The positive electron ionization mode was used at 70-electron volt.

\section{Results and Discussion}

3.1. Photocatalytic Transformation of Trifluralin (1). GC-MS analysis of unirradiated and irradiated samples (6 hr and $9 \mathrm{hr}$ ) of trifluralin (1) is shown in Figures 1(a), 1(b), and 1(c), respectively. Figure 1(a) indicates a single peak at retention time $\left(R_{t}\right) 9.4$ corresponding to trifluralin confirmed by comparing molecular ion and mass fragmentation pattern with NIST library. Figures 1(b) and 1(c) indicate formation of several intermediate products on irradiation of trifluralin in the presence of $\mathrm{TiO}_{2}$. It is interesting to note that, on prolonged irradiation of trifluralin for 9 hours, concentration of few intermediates decreases whereas some additional intermediates are formed. Few products that were characterized based on molecular ion, on mass fragmentation patterns, and also on comparison with NIST library are shown in Table 1.

The probable degradation pathway of trifluralin (1) under photocatalytic conditions showing the formation of various products is shown in Scheme 1. The complete reduction of one of the nitro groups of $\mathbf{1}$ to amino group leads to the formation of $\mathbf{4}$. Partial reduction of nitro group of $\mathbf{4}$ gives nitroso derivative $\mathbf{8}$ which upon cyclization and subsequent loss of water molecule leads to the formation of product $\mathbf{1 1}$. Cyclization of 4, prior to reduction of nitro group, leads to $\mathrm{N}$-oxide derivative 7. Similarly, partial reduction of one of the nitro groups of $\mathbf{1}$ leads to intermediate $\mathbf{5}$ which upon further loss of water molecule gives benzimidazole derivative 9 . Loss of $\mathrm{N}$-propyl group of $\mathbf{9}$ leads to the formation of $\mathbf{1 2}$. The formation of benzimidazoles $(\mathbf{9}, \mathbf{1 1}$, and $\mathbf{1 2})$ and benzimidazole$\mathrm{N}$-oxide derivative 7 was not unexpected. Previous studies have shown that $\mathrm{N}$-alkyl-o-nitroanilines are readily cyclised to form benzimidazoles and benzimidazole-N-oxides upon irradiation at $2537 \AA$ and upon irradiation through Pyrex $[41,42]$. The entire aspects of chemical interaction between aromatic nitro groups and ortho side chains had been the subject of a review by Preston and Tennant [43]. Alternatively loss of one of the propyl groups and hydroxylation of another alkyl group of $\mathbf{1}$ may lead to $\mathbf{6}$. Partial reduction of one of the nitro groups of $\mathbf{6}$ gives 10. It is worth mentioning that dealkylation and reduction of nitro group to amino via nitroso under photocatalytic conditions are well documented in the literature $[7,11,44-46]$. 


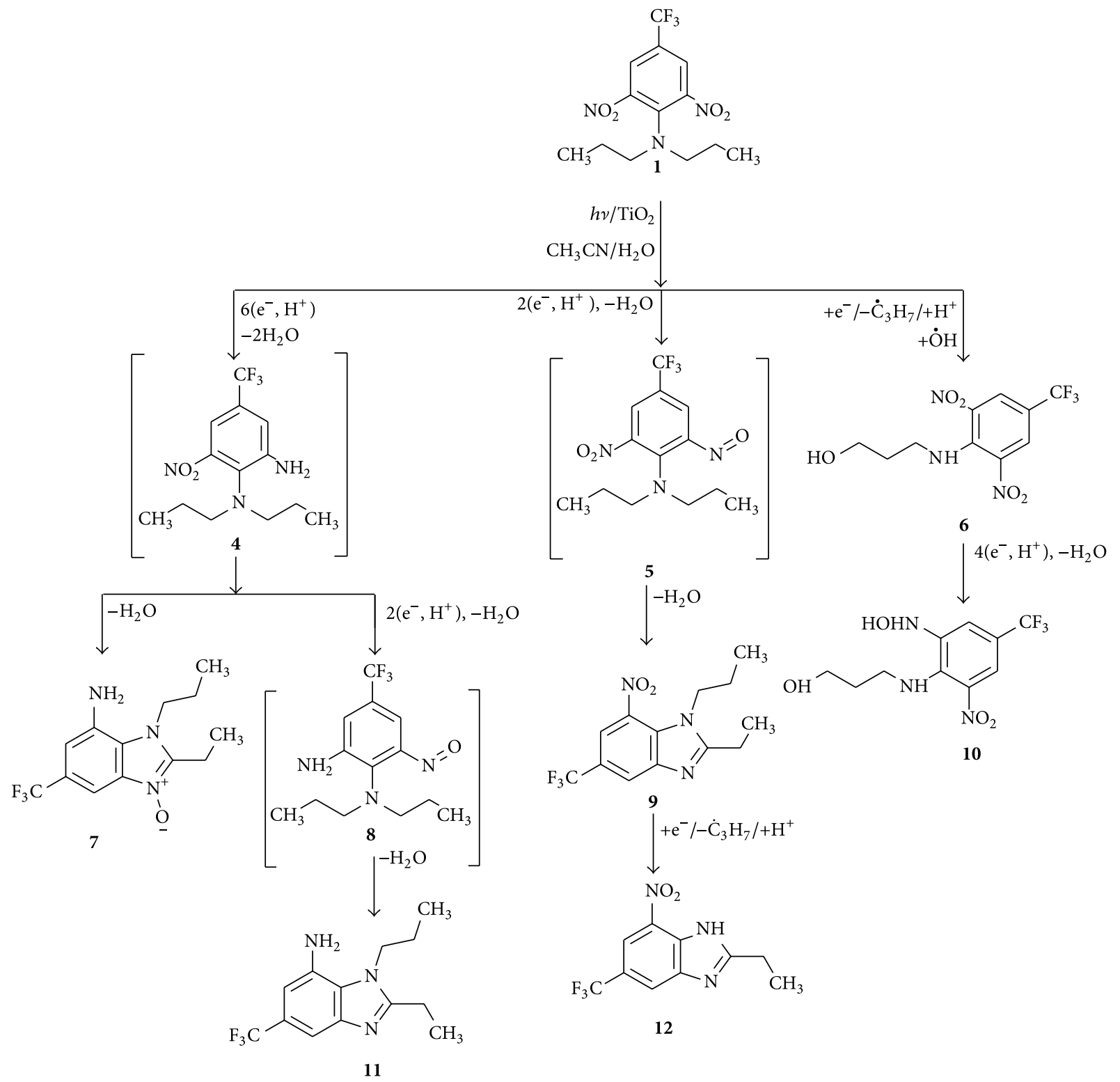

Scheme 1: Probable pathway for the degradation of trifluralin (1) catalyzed by $\mathrm{TiO}_{2}$ in the presence of UV light.

3.2. Photocatalytic Transformation of Clodinafop-Propargyl (2). Figures 2(a) and 2(b) show the gas chromatogram of unirradiated and irradiated sample $(3 \mathrm{hr})$ of clodinafoppropargyl (2), respectively. The single peak at retention time $\left(R_{t}\right)$ of $22.9 \mathrm{~min}$ in Figure 2(a) corresponds to clodinafoppropargyl confirmed by comparing its molecular ion and mass fragmentation pattern with those in NIST library. Figure 2(b) shows the gas chromatogram of clodinafoppropargyl after irradiation for three hours indicating the formation of several intermediate products along with some unchanged starting material. The structures of eight degradation products have been confirmed on the basis of their molecular ion and mass fragmentation patterns shown in Table 2.
The formation of these products during photocatalytic degradation of clodinafop-propargyl 2 can be understood in terms of the pathway shown in Scheme 2. The main reaction routes for the degradation involve dehalogenation, aromatic ring substitution, reduction of triple bond to double bond, and cleavage of ether linkage.

Loss of fluorine in $\mathbf{2}$ followed by hydroxylation may lead to the formation of $\mathbf{1 3}$ which in turn may form product $\mathbf{1 6}$ by the loss of pyridyl moiety via cleavage of the ether linkage. Alternatively, demethylation and the loss of propargyl alcohol radical followed by hydroxylation lead to product 14 . Cleavage of the ether linkage in $\mathbf{1 4}$ may lead to the formation of 5-chloro-3-fluoropyridin-2-ol (17) and 2-phenoxyacetic acid (18). Loss of acetic acid moiety of $\mathbf{1 4}$ may give product $\mathbf{1 9}$ 
TABLE 2: Probable products formed during the photocatalytic degradation of clodinafop-propargyl (2) along with their retention time and corresponding mass fragmentation.

\begin{tabular}{|c|c|c|c|}
\hline $\begin{array}{l}\text { Retention } \\
\text { Time (min) }\end{array}$ & Name & Confirmed By & Mass fragmentation \\
\hline 24.1 & $\begin{array}{l}\text { Prop-2-ynyl } \\
\text { 2-(4-(5-chloro-3-hydroxypyridin-2- } \\
\text { yloxy)phenoxy)propanoate } \\
\text { (13) }\end{array}$ & MS & $\begin{array}{l}346.934\left(\mathrm{M}^{+}\right) / 348.926,310.977,281.030 \\
\text { 264.022/266.022, 235.985, 219.987, 207.977, 179.996, } \\
172.055,146.055,127.986,99.903,90.983,72.570,62.376\end{array}$ \\
\hline 24.0 & $\begin{array}{l}\text { Allyl 2-(4-(5-chloro-3-fluoropyridin-2- } \\
\text { yloxy)-2-hydroxyphenoxy)propanoate } \\
(\mathbf{2 0})\end{array}$ & MS & $\begin{array}{l}366.986\left(\mathrm{M}^{+}\right) / 368.852,266.016 / 268.014, \\
237.979 / 238.985,221.978,209.977,176.026,159.034, \\
129.981,90.894\end{array}$ \\
\hline 23.9 & $\begin{array}{l}\text { Allyl 2-(4-(3-fluoro-5-hydroxypyridin-2- } \\
\text { yloxy)phenoxy)propanoate } \\
\text { (21) }\end{array}$ & MS & $\begin{array}{l}333.962\left(\mathrm{M}^{+}\right), 226.014 / 228.012,198.932,183.971,170.949, \\
154.030,138.009,124.974,110.962,92.868\end{array}$ \\
\hline 22.9 & $\begin{array}{l}\text { 2-Propynyl (R)-2-[4-(5-chloro-3-fluoro-2- } \\
\text { pyridinyloxy)phenoxy]propionate } \\
\text { (clodinafop-propargyl) (2) }\end{array}$ & NIST & $\begin{array}{l}348.943\left(\mathrm{M}^{+}\right) / 350.912 / 351.911,310.992,266.32 / 268.014 \\
\text { 251.997, } 237.995 / 239.977,221.978,209.976,204.010 \\
181.988,176.025,159.034,129.980,109.936,90.894 \\
75.672,62.374\end{array}$ \\
\hline 17.6 & $\begin{array}{l}\text { 2-(4-(5-Chloro-3-fluoropyridin-2- } \\
\text { yloxy)phenoxy)acetaldehyde } \\
\text { (14) }\end{array}$ & MS & $\begin{array}{l}281.083\left(\mathrm{M}^{+}\right), 237.977 / 238.996 / 240.983,210.984 \\
176.025 / 177.028,149.033,129.982,80.755,62.375\end{array}$ \\
\hline 16.2 & $\begin{array}{l}\text { 4-(5-Chloro-3-fluoropyridin-2- } \\
\text { yloxy)phenol } \\
\text { (19) }\end{array}$ & MS & $\begin{array}{l}237.979\left(\mathrm{M}^{+}\right) / 238.996 / 240.983,210.984,204.010 \\
176.029 / 177.028,156.031,149.032,129.980,108.982, \\
93.875,80.755,75.660,64.444\end{array}$ \\
\hline 13.9 & $\begin{array}{l}\text { Prop-2-ynyl } \\
\text { 2-(4-hydroxyphenoxy)propanoate (16) }\end{array}$ & MS & $\begin{array}{l}220.039\left(\mathrm{M}^{+}\right) / 221.043,137.056 / 138.060,109.994 / 111.003 \\
80.755,64.444\end{array}$ \\
\hline 5.9 & 2-Phenoxyacetic acid (18) & MS & $152.038\left(\mathrm{M}^{+}\right), 109.994,80.755$ \\
\hline 3.8 & 5-Chloro-3-fluoropyridin-2-ol (17) & MS & $146.983\left(\mathrm{M}^{+}\right) / 148.979,118.976 / 120.986,91.831,56.180$ \\
\hline
\end{tabular}

Note that the number in the parenthesis corresponds to the number of the compound in the degradation scheme.

TABLE 3: Probable products formed during the photocatalytic degradation of 1,2-dichloro-4-nitrobenzene (3) along with their retention time and corresponding mass fragmentation.

\begin{tabular}{|c|c|c|c|}
\hline $\begin{array}{l}\text { Retention time } \\
(\mathrm{min})\end{array}$ & Name & Confirmed By & Mass fragmentation \\
\hline 16.6 & 1,2-Bis(3,4-dichlorophenyl)diazene (27) & NIST & $\begin{array}{l}318\left(\mathrm{M}^{+}\right) / 319.947,172.975 / 174.9,144.963 / 146.9,108.984 \\
75.021\end{array}$ \\
\hline 8.3 & Dichloronitrophenol (22) & NIST & $\begin{array}{l}206.957\left(\mathrm{M}^{+}\right) / 208.9 / 210.970,176.991 / 178.9,160.969 \\
148.969,132.969 / 134.967,124.989,112.989,96.986 \\
86.969,72.986,62.016\end{array}$ \\
\hline 6.7 & 2-Chloro-5-nitrophenol (23) & NIST & $\begin{array}{l}172.990\left(\mathrm{M}^{+}\right) / 174.990,142.992 / 144.992,126.995,107.011 \\
98.994,91.012,72.979,63.018,53.001\end{array}$ \\
\hline 6.6 & 3,4-Dichloroaniline (25) & NIST & $160.98\left(\mathrm{M}^{+}\right) / 162.9 / 164.979,126.008,98.995,90.027$ \\
\hline 6.3 & 3,4-Dichlorophenol (24) & NIST & $161.967\left(\mathrm{M}^{+}\right) / 163.9 / 165.962,144.707,98.995,63.020$ \\
\hline 6.2 & 1,2-Dichloro-4-nitrobenzene (3) & NIST & $\begin{array}{l}190.987\left(\mathrm{M}^{+}\right) / 192.978 / 194.970,160.974 / 162.971 \\
144.983 / 146.974,132.972 / 133.9,108.995 / 110.987,83.978 \\
\text { 74.016/75.024/73.001, 50.017 }\end{array}$ \\
\hline
\end{tabular}

Note that the number in the parenthesis corresponds to the number of the compound in the degradation scheme.

which in turn may form $\mathbf{1 7}$ by the expulsion of phenoxide radical. The difference of $\mathbf{1 8}$ mass units between $20(\mathrm{~m} / \mathrm{z}$ $367)$ and 2 ( $\mathrm{m} / \mathrm{z} 349)$ suggests that, before hydroxylation, precursor compound $\mathbf{1 5}$ is formed via the partial reduction of triple bond to double bond. Alternatively, dechlorination of $\mathbf{1 5}$ followed by hydroxylation may lead to the formation of product 21 . It is interesting to note that compounds $\mathbf{1 3}$ and $\mathbf{1 7}$ have also been reported to be formed during the direct photolysis of $\mathbf{2}$ on glass surface under sunlight and UV light [47].

3.3. Photocatalytic Transformation of 1,2-Dichloro-4-Nitrobenzene (3). Gas chromatograms of unirradiated and irradiated samples (3 and $9 \mathrm{hr}$ ) of 1,2-dichloro-4nitrobenzene (3) are shown in Figures 3(a), 3(b), and 3(c), respectively. It is obvious from Figure 3(a) that unirradiated 


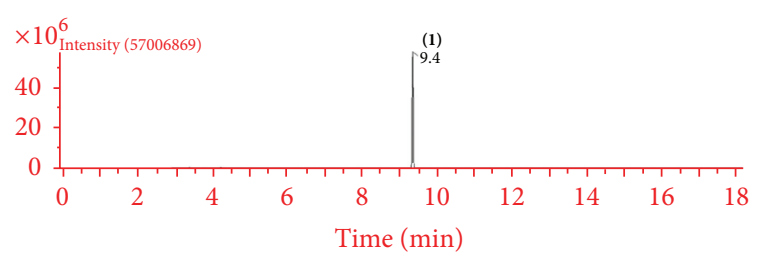

(a) Unirradiated trifluralin

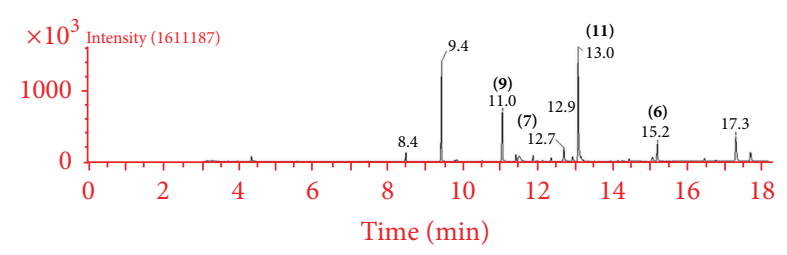

(b) Irradiated sample (6 hr)

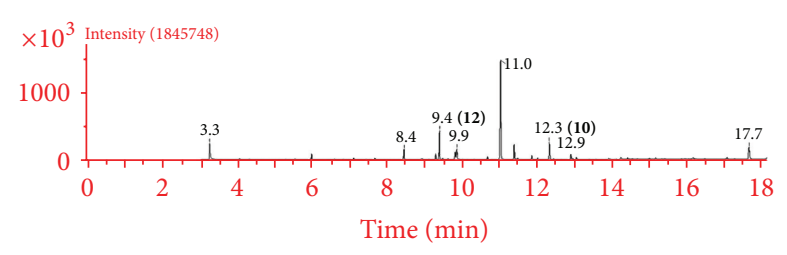

(c) Irradiated sample $(9 \mathrm{hr})$

FIGURE 1: Gas chromatogram of trifluralin (1): (a) unirradiated trifluralin, (b) irradiated mixture $(6 \mathrm{hr})$, and (c) irradiated mixture (9 hr).

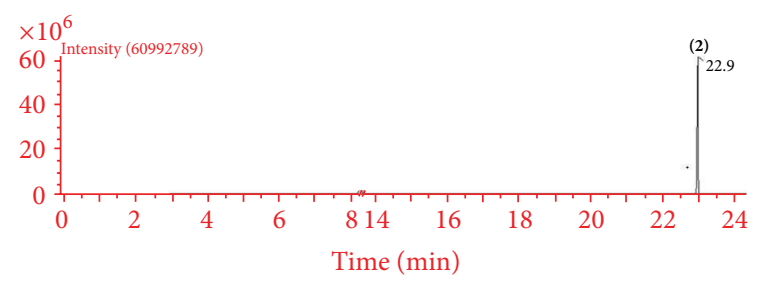

(a) Unirradiated clodinafop-propargyl

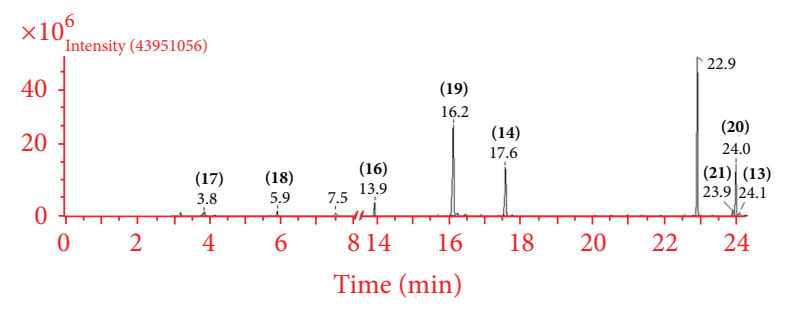

(b) Irradiated sample (3 hr)

FIgURE 2: Gas chromatogram of clodinafop-propargyl (2): (a) unirradiated clodinafop-propargyl, (b) irradiated sample ( $3 \mathrm{hr})$.

sample of compound 3 shows a single peak at a retention time $\left(R_{t}\right)$ of 6.2 minutes corresponding to 1,2-dichloro-4nitrobenzene confirmed by comparing its molecular ion and mass fragmentation pattern with those in NIST library. Gas chromatogram of the irradiated sample (3 hours) indicates the formation of several degradation products along with some unchanged starting material. The prolonged irradiation for nine hours shows increase in the concentration of few

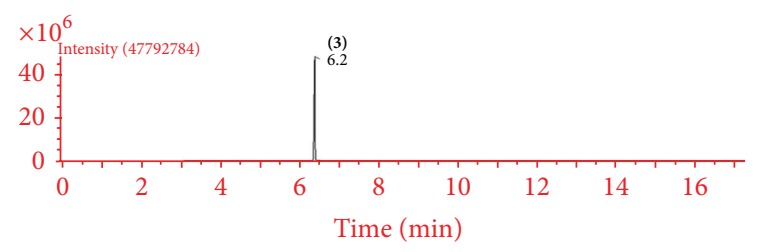

(a) Unirradiated 1,2-dichloro-4-nitrobenzene

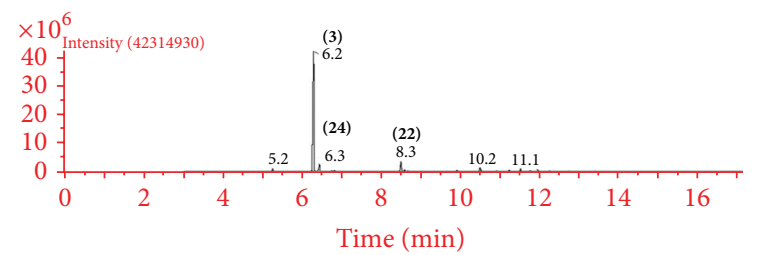

(b) Irradiated sample $(3 \mathrm{hr})$

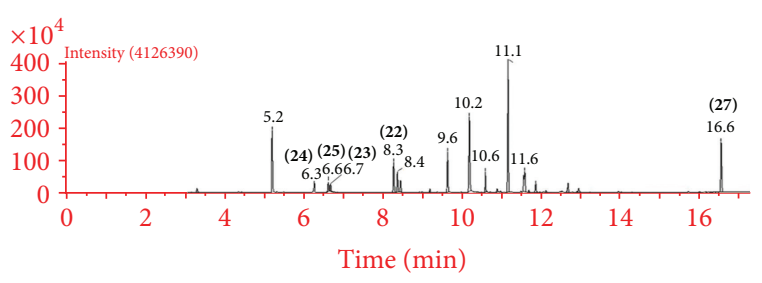

(c) Irradiated sample $(9 \mathrm{hr})$

FIGURE 3: Gas chromatogram of 1,2-dichloro-4-nitrobenzene (3): (a) unirradiated 1,2-dichloro-4-nitrobenzene, (b) irradiated sample (3 hr), and (c) irradiated sample (9 hr).

products as well as formation of several new products. The structure of few products corresponding to peaks at retention times $\left(R_{t}\right)$ of $6.3 \mathrm{~min}, 6.6 \mathrm{~min}, 6.7 \mathrm{~min}, 8.3 \mathrm{~min}$, and $16.6 \mathrm{~min}$ has been confirmed on the basis of their molecular ion, on mass fragmentation pattern, and also on comparison of their mass fragmentation data with that in NIST library. The molecular ion and mass fragmentation pattern of 1,2-dichloro-4-nitrobenzene and its different degradation products are shown in Table 3 . The probable pathway showing the transformation of 1,2-dichloro-4-nitrobenzene into various intermediate products in the presence of $\mathrm{TiO}_{2}$ in acetonitrile water mixture is shown in Scheme 3.

The main routes of transformation of 1,2-dichloro-4nitrobenzene under photocatalytic conditions were found to be dehalogenation, denitration, hydroxylation, and dimerization. Thus the direct hydroxylation of $\mathbf{3}$ may give $\mathbf{2 2}$ whereas substitution of one of the chlorines by hydroxyl group leads to 23 .

Alternatively denitration of 3 followed by hydroxylation may give dichlorophenol 24. Complete reduction of nitro group of $\mathbf{3}$ to amino group via nitroso derivative $\mathbf{2 6}$ gives dichloroaniline derivative $\mathbf{2 5}$. Reaction of $\mathbf{2 5}$ with nitroso derivative $\mathbf{2 6}$ followed by loss of water gives diazene derivative 27. It is interesting to note that reduction of nitro group to amino via nitroso under photocatalytic conditions is well documented in the literature [11, 44-46]. 


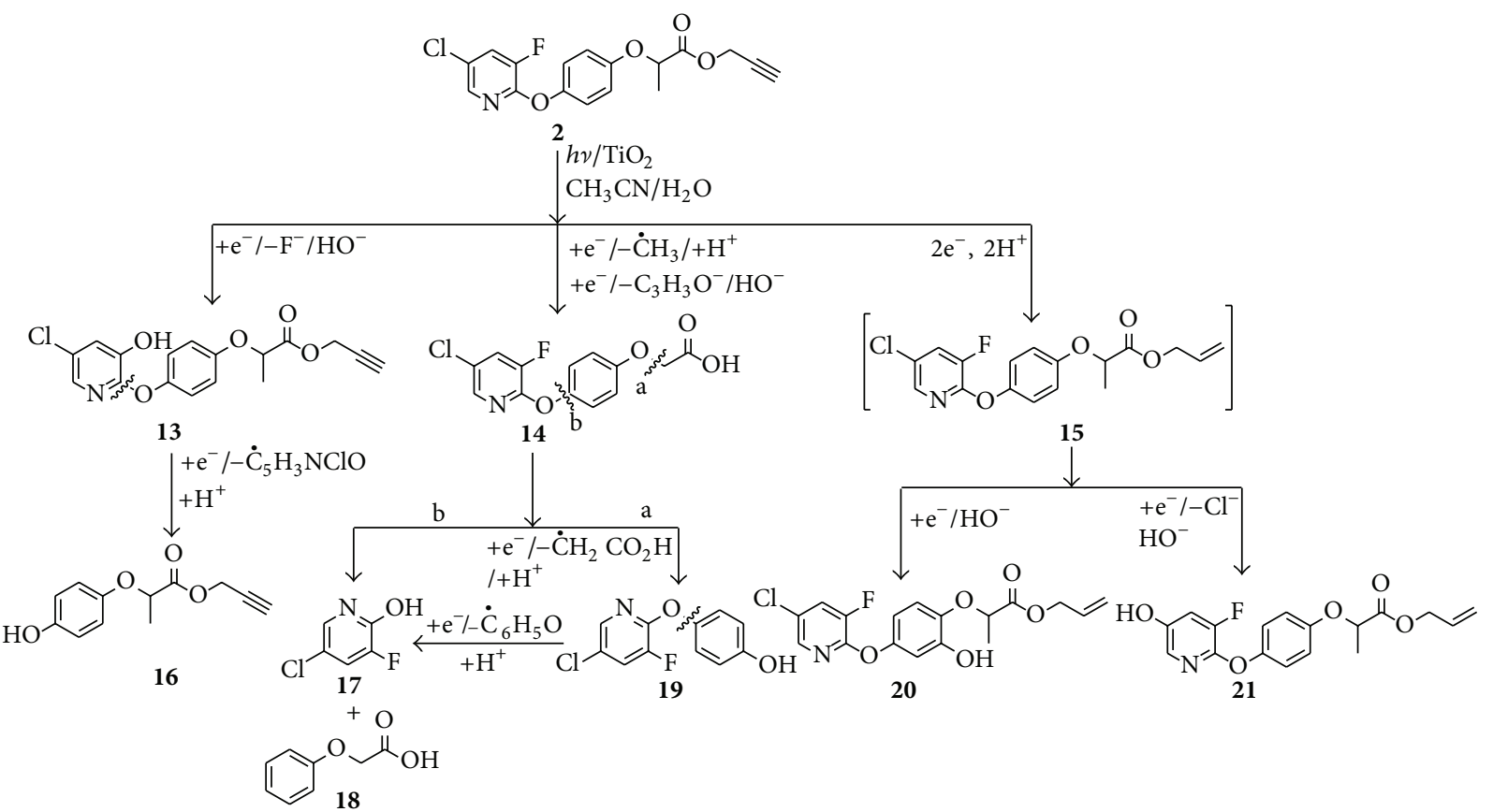

SCHEME 2: Possible route for the degradation of clodinafop-propargyl (4) in $\mathrm{CH}_{3} \mathrm{CN} / \mathrm{H}_{2} \mathrm{O}$ medium catalyzed by $\mathrm{TiO}_{2}$ in the presence of UV light.

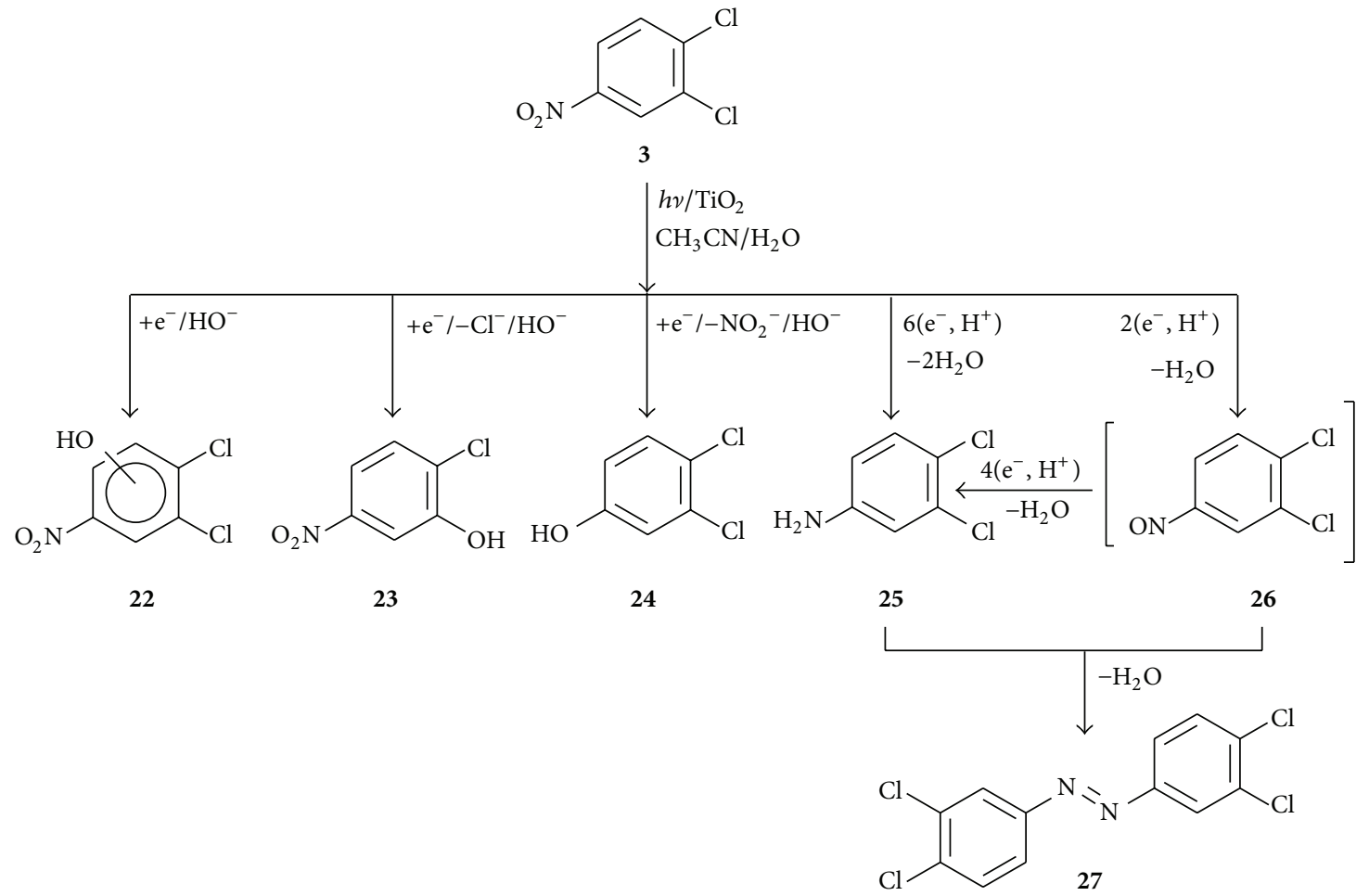

SCHEME 3: Probable phototransformation of 1,2-dichloro-4-nitrobenzene (3) in $\mathrm{CH}_{3} \mathrm{CN} / \mathrm{H}_{2} \mathrm{O}$ medium catalyzed by $\mathrm{TiO}_{2}$ in the presence of UV light. 


\section{Conclusion}

Photocatalytic transformation of organic pollutants is an important factor to understand their fate and environmental behavior. The three pesticide derivatives studied underwent photocatalytic degradation and comprehensive pathways of transformation were proposed by identification of intermediate products. The GC-MS technique proved efficient for the detection and identification of the formed degradation products. The photocatalytic degradation of pesticides of different chemical structures demonstrated markedly different degradation pathways. Loss of alkyl groups, halogen(s), cleavage of alkoxy and ester bonds, denitration, oxidation of side chain, cyclization, and reduction of alkyne to alkene and nitro to amino group were found to be the typical degradation routes. The study is essential in revealing the extent of photostability and the precise reaction mechanisms of photocatalytic transformation of pesticides and contributes to the apt understanding of environmental behavior of pesticides.

\section{Conflict of Interests}

The authors declare that there is no conflict of interests regarding the publication of this paper.

\section{Acknowledgments}

Financial supports from UGC, New Delhi, and CSTUP, Lucknow, for Research Project Grants, DRS-1 (SAP) from UGC, New Delhi, to the Department of Chemistry, Aligarh Muslim University, Aligarh, and the Award of Senior Research Fellowship from UGC New Delhi to Niyaz A. Mir are gratefully acknowledged. The authors would like to acknowledge the support of Solid State and Structural Chemistry Unit, Indian Institute of Science, Bangalore, India, and Department of Earth System Sciences, Yonsei University, Republic of Korea.

\section{References}

[1] D. M. Blake, "Bibliography of work on the Photocatalytic removal of hazardous compounds from water and air. (1994), (1995), (1997), (1999) and (2001)," NREL/TP 430-22197, National Renewable Energy Laboratory, Golden, Colorado.

[2] M. Janus, E. Kusiak-Nejman, and A. W. Morawski, "Determination of the photocatalytic activity of $\mathrm{TiO} 2$ with high adsorption capacity," Reaction Kinetics, Mechanisms and Catalysis, vol. 103, no. 2, pp. 279-288, 2011

[3] E. B. Azevedo, A. R. Tôrres, F. R. Aquino Neto, and M. Dezotti, " $\mathrm{TiO}_{2}$-Photocatalyzed degradation of phenol in saline media in an annular reactor: hydrodynamics, lumped kinetics, intermediates, and acute toxicity," Brazilian Journal of Chemical Engineering, vol. 26, no. 1, pp. 75-87, 2009.

[4] R. Vinu and G. Madras, "Environmental remediation by photocatalysis," Journal of the Indian Institute of Science, vol. 90, no. 2, pp. 189-230, 2010.

[5] J. Herrmann, "Photocatalysis fundamentals revisited to avoid several misconceptions," Applied Catalysis B: Environmental, vol. 99, no. 3-4, pp. 461-468, 2010.
[6] N. A. Mir, M. M. Haque, A. Khan, M. Muneer, and S. Vijayalakshmi, "Photocatalytic degradation of herbicide Bentazone in aqueous suspension of $\mathrm{TiO}_{2}$ : mineralization, identification of intermediates and reaction pathways," Environmental Technology, vol. 35, no. 4, pp. 407-415, 2014.

[7] N. A. Mir, A. Khan, M. Muneer, and S. Vijayalakhsmi, "Photocatalytic degradation of a widely used insecticide Thiamethoxam in aqueous suspension of $\mathrm{TiO}_{2}$ : adsorption, kinetics, product analysis and toxicity assessment," Science of the Total Environment, vol. 458-460, pp. 388-398, 2013.

[8] A. Bianco Prevot, M. Vincenti, A. Bianciotto, and E. Pramauro, "Photocatalytic and photolyric transformation of chloramben in aqueous solutions," Applied Catalysis B: Environmental, vol. 22, no. 2, pp. 149-158, 1999.

[9] A. B. Prevot, E. Pramauro, and M. De la Guardia, "Photocatalytic degradation of carbaryl in aqueous $\mathrm{TiO}_{2}$ suspensions containing surfactants," Chemosphere, vol. 39, no. 3, pp. 493502, 1999.

[10] S. Parra, V. Sarria, S. Malato, P. Péringer, and C. Pulgarin, "Photochemical versus coupled photochemical-biological flow system for the treatment of two biorecalcitrant herbicides: metobromuron and isoproturon," Applied Catalysis B: Environmental, vol. 27, no. 3, pp. 153-168, 2000.

[11] I. K. Konstantinou and T. A. Albanis, "Photocatalytic transformation of pesticides in aqueous titanium dioxide suspensions using artificial and solar light: intermediates and degradation pathways," Applied Catalysis B: Environmental, vol. 42, no. 4, pp. 319-335, 2003.

[12] A. P. F. M. de Urzedo, M. E. R. Diniz, C. C. Nascentes, R. R. Catharino, M. N. Eberlin, and R. Augusti, "Photolytic degradation of the insecticide thiamethoxam in aqueous medium monitored by direct infusion electrospray ionization mass spectrometry," Journal of Mass Spectrometry, vol. 42, no. 10, pp. 1319-1325, 2007.

[13] E. Gikas, N. G. Papadopoulos, F. N. Bazoti, G. Zalidis, and A. Tsarbopoulos, "Use of liquid chromatography/electrospray ionization tandem mass spectrometry to study the degradation pathways of terbuthylazine (TER) by Typha latifolia in constructed wetlands: identification of a new ter metabolite," Rapid Communications in Mass Spectrometry, vol. 26, no. 2, pp. 181188,2012

[14] R. P. Lopes, A. P. F. M. de Urzedo, C. C. Nascentes, and R. Augusti, "Degradation of the insecticides thiamethoxam and imidacloprid by zero-valent metals exposed to ultrasonic irradiation in water medium: electrospray ionization mass spectrometry monitoring," Rapid Communications in Mass Spectrometry, vol. 22, no. 22, pp. 3472-3480, 2008.

[15] Reregistration Eligibility Decision: Trifluralin, 1996.

[16] R. Grover, J. D. Wolt, A. J. Cessna, and H. B. Schiefer, "Environmental fate of trifluralin," Reviews of Environmental Contamination and Toxicology, vol. 153, pp. 1-64, 1997.

[17] USDA, National Agricultural Statistics Service, Agricultural chemical usage 2001, Field Crop Summary, 2002.

[18] G. W. Probst, J. B. Tepe, P. C. Kearney, and D. D. Kaufman, “Trifluralin and related compounds," in Degradation of Herbicides, pp. 255-282, Marcel Dekker, New York, NY, USA, 1969.

[19] G. W. Probst, T. Golab, and L. W. Wright, Herbicides: Chemistry, Degradation and Mode of Action, Marcel Dekker, New York, NY, USA, 1975.

[20] G. W. Probst, T. Golab, R. J. Herberg et al., "Fate of trifluralin in soils and plants," Journal of Agricultural and Food Chemistry, vol. 15 , no. 4 , pp. 592-599, 1967. 
[21] S. A. Greene and R. P. Pohanish, Sittigs Handbook of Pesticides and Agricultural Chemicals, William Andrew Publishing, New York, NY, USA, 2005.

[22] L. S. Brar, U. S. Walia, and B. K. Dhaliwal, "Bioefficacy of new herbicides for the control of resistant phalaris minor in wheat," Pesticide Research Journal, vol. 11, no. 2, pp. 177-180, 1999.

[23] R. E. Blackshaw, G. Semach, and T. Entz, "Postemergence control of foxtail barley (Hordeum jubatum) seedlings in spring wheat (Triticum aestivum) and flax (Linum usitatissimum)," Weed Technology, vol. 12, no. 4, pp. 610-616, 1998.

[24] M. Airoldi, U. D. Alberti, and H. T. R. Gut, "New postemergence graminicide forwheat," Informatore Fitopatologico, vol. 47, pp. 57-60, 1997.

[25] C. E. Bell, "Field evaluation of MKH-6561 for Phalaris minor control in durum wheat," in Proceedings of the Brighton Crop Protection Conference: Weeds, pp. 211-216, 1999.

[26] U. S. Walia, L. S. Brar, and B. K. Dhaliwal, "Performance of Clodinafop and Fenoxapropp-ethyl for control of resistant Phalaris minor in wheat," Indian Journal of Weed Science, vol. 30, pp. 48-50, 1998.

[27] P. Barnwell and A. H. Cobb, "Graminicide antagonism by broadleaf weed herbicides," Pesticide Science, vol. 41, no. 2, pp. 77-85, 1994.

[28] A. V. Toole, D. G. Crosby, and S. Simons, "Dissipation of Fenoxaprop ethyl under different conditions," Environmental Toxicology and Chemistry, vol. 8, pp. 1171-1176, 1999.

[29] R. E. Alcock, A. Sweetman, and K. C. Jones, "Assessment of organic contaminant fate in waste water treatment plants. I: selected compounds and physicochemical properties," Chemosphere, vol. 38, no. 10, pp. 2247-2262, 1999.

[30] National Toxicology Program, "NTP technical report on toxicity studies of 2-chloronitrobenzene and 4-chloronitrobenzene administered by inhalation to F344/N rats and B6C3F1 mice," Toxicity Report Series No. 33, NIH Publication No. 93-3382, 1993.

[31] D. E. Rickert and S. D. Held, "Metabolism of chloronitrobenzenes by isolated rat hepatocytes," Drug Metabolism and Disposition, vol. 18, no. 1, pp. 5-9, 1990.

[32] A. G. Livingston and A. Willacy, "Degradation of 3,4dichloroaniline in synthetic and industrially produced wastewaters by mixed cultures freely suspended and immobilized in a packed-bed reactor," Applied Microbiology and Biotechnology, vol. 35, no. 4, pp. 551-557, 1991.

[33] M. P. Yurawecz and B. J. Puma, "Identification of chlorinated nitrobenzene residues in Mississippi River fish," Journal of the Association of Official Analytical Chemists, vol. 66, no. 6, pp. 1345-1352, 1983.

[34] R. S. Nair, F. R. Johannsen, G. J. Levinskas, and J. B. Terrill, "Subchronic inhalation toxicity of p-nitroaniline and pnitrochlorobenzene in rats," Fundamental and Applied Toxicology, vol. 6, no. 4, pp. 618-627, 1986.

[35] R. S. Nair, F. R. Johannsen, G. J. Levinskas, and J. B. Terrill, "Assessment of toxicity of o-nitrochlorobenzene in rats following a 4-week inhalation exposure," Fundamental and Applied Toxicology, vol. 7, no. 4, pp. 609-614, 1986.

[36] G. S. Travlos, J. Mahler, H. A. Ragan, B. J. Chou, and J. R. Bucher, "Thirteen-week inhalation toxicity of 2- and 4chloronitrobenzene in $\mathrm{F} 344 / \mathrm{N}$ rats and B6C3F1 mice," Fundamental and Applied Toxicology, vol. 30, no. 1, pp. 75-92, 1996.

[37] Q. Li, M. Minami, and H. Inagaki, "Acute and subchronic immunotoxicity of p-chloronitrobenzene in mice. I. Effect on natural killer, cytotoxic T-lymphocyte activities and mitogenstimulated lymphocyte proliferation," Toxicology, vol. 127, no. 13, pp. 223-232, 1998.

[38] Q. Li, M. Minami, T. Hanaoka, and Y. Yamamura, "Acute immunotoxicity of p-chloronitrobenzene in mice: II. Effect of p-chloronitrobenzene on the immunophenotype of murine splenocytes determined by flow cytometry," Toxicology, vol. 137, no. 1, pp. 35-45, 1999.

[39] R. I. Bickley, T. Gonzalez-Carreno, J. S. Lees, L. Palmisano, and R. J. D. Tilley, "A structural investigation of titanium dioxide photocatalysts," Journal of Solid State Chemistry, vol. 92, no. 1, pp. 178-190, 1991.

[40] N. A. Mir, M. M. Haque, A. Khan, K. Umar, M. Muneer, and S. Vijayalakshmi, "Semiconductor mediated photocatalysed reaction of two selected organic compounds in aqueous suspensions of Titanium dioxide," Journal of Advanced Oxidation Technologies, vol. 15, no. 2, pp. 380-391, 2012.

[41] D. J. Neadle and R. J. Pollitt, "The photolysis of $N$ 2,4-dinitrophenylamino-acids to give 2-substituted 6nitrobenzimidazole 1-oxides," Journal of the Chemical Society C: Organic Chemistry, pp. 1764-1766, 1967.

[42] R. Fielden, O. Meth-Cohn, and H. Suschitzky, "Thermal and photolytic cyclisation, rearrangement, and denitration reactions of o-nitro-t-anilines," Tetrahedron Letters, vol. 11, no. 15, pp. 1229-1234, 1970.

[43] P. N. Preston and G. Tennant, "Synthetic methods involving neighboring group interaction in ortho-substituted nitrobenzene derivatives," Chemical Reviews, vol. 72, no. 6, pp. 627-677, 1972.

[44] P. Piccinini, C. Minero, M. Vincenti, and E. Pelizzetti, "Photocatalytic interconversion of nitrogen-containing benzene derivatives," Journal of the Chemical Society - Faraday Transactions, vol. 93, no. 10, pp. 1993-2000, 1997.

[45] A. Maldotti, L. Andreotti, A. Molinari, S. Tollari, A. Penoni, and S. Cenini, "Photochemical and photocatalytic reduction of nitrobenzene in the presence of cyclohexene," Journal of Photochemistry and Photobiology A: Chemistry, vol. 133, no. 12, pp. 129-133, 2000.

[46] V. Brezová, P. Tarábek, D. Dvoranová, A. Stako, and S. Biskupic, "EPR study of photoinduced reduction of nitroso compounds in titanium dioxide suspensions," Journal of Photochemistry and Photobiology A: Chemistry, vol. 155, no. 1-3, pp. 179-198, 2003.

[47] S. Roy and S. B. Singh, "Phototransformation of clodinafoppropargyl," Journal of Environmental Science and Health B: Pesticides, Food Contaminants, and Agricultural Wastes, vol. 40, no. 4, pp. 525-534, 2005. 

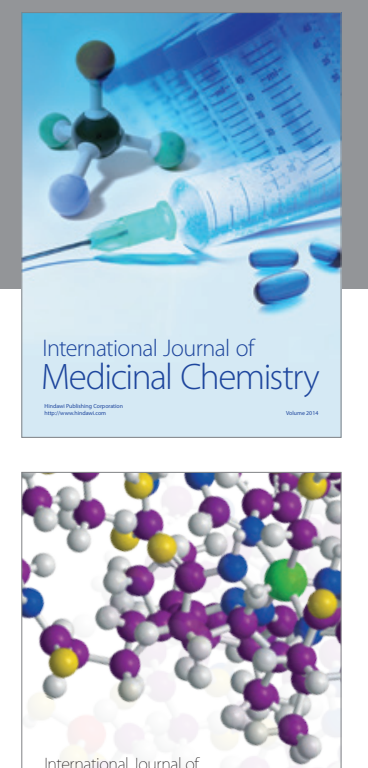

\section{Carbohydrate} Chemistry

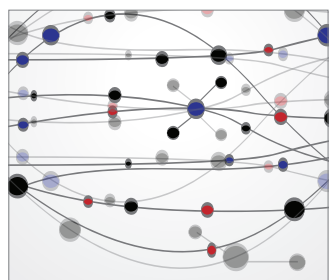

The Scientific World Journal
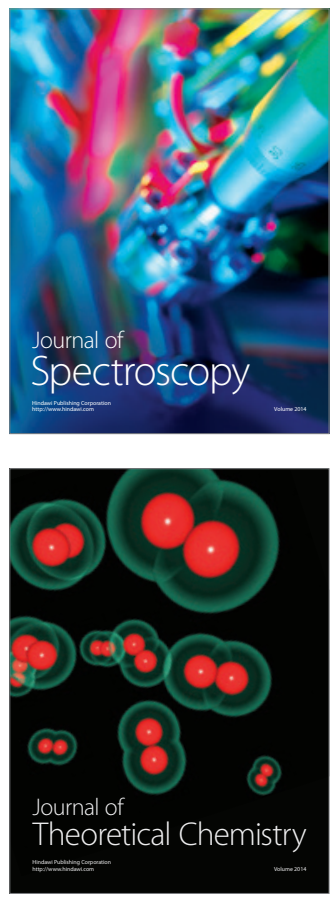
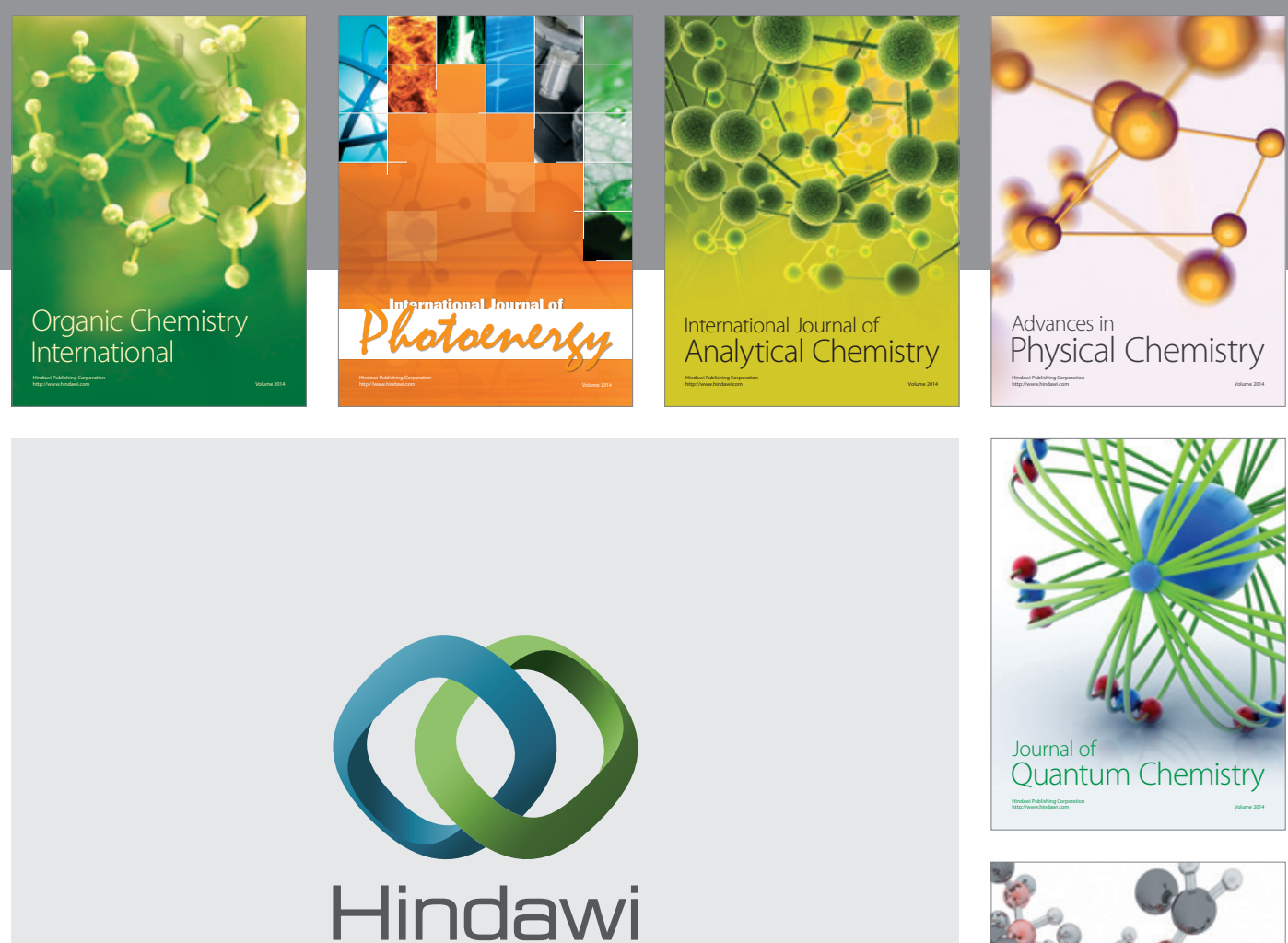

Submit your manuscripts at

http://www.hindawi.com

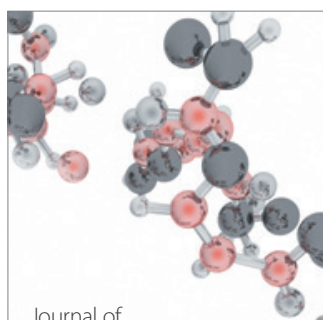

Analytical Methods

in Chemistry

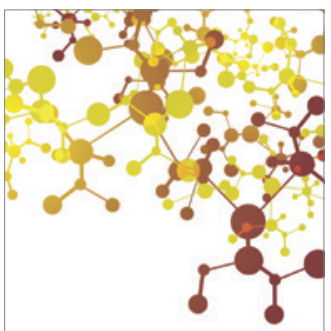

Journal of

Applied Chemistry

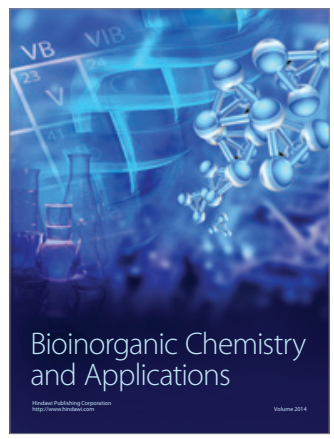

Inorganic Chemistry
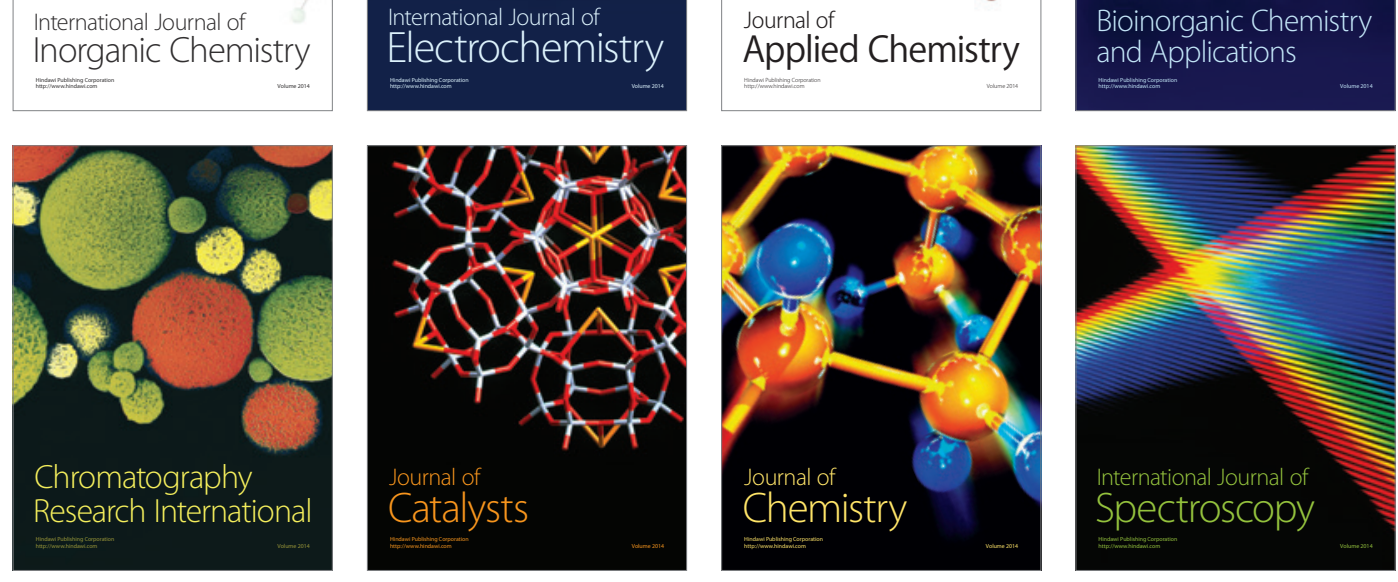